\title{
Chemical Speciation and Potential Mobility of Heavy Metals in the Soils of Onitsha South Local Government Area Anambra Nigeria
}

\author{
Ochiagha Kate Ekwutosi*, Okoye Patrice-Anthony Chudi, Eboagu Nkiru Charity \\ Department of Pure and Industrial Chemistry, Faculty of Physical Sciences Nnamdi Azikiwe University, Awka, Nigeria \\ Email address: \\ ochiagha2007@yahoo.com (O. K. Ekwutosi) \\ ${ }^{*}$ Corresponding author \\ To cite this article: \\ Ochiagha Kate Ekwutosi, Okoye Patrice-Anthony Chudi, Eboagu Nkiru Charity. Chemical Speciation and Potential Mobility of Heavy \\ Metals in the Soils of Onitsha South Local Government Area Anambra Nigeria. American Journal of Applied Chemistry. \\ Vol. 8, No. 3, 2020, pp. 74-81. doi: 10.11648/j.ajac.20200803.12
}

Received: May 4, 2020; Accepted: June 8, 2020; Published: July 4, 2020

\begin{abstract}
The understanding of chemical forms of heavy metals and how they associate with themselves is very essential in studying the potential mobility and risk assessment of heavy metals in soils. This study determined the spatial distribution and mobility of $\mathrm{Mn}, \mathrm{Ni}, \mathrm{Zn}, \mathrm{Cr}, \mathrm{Cu}, \mathrm{Pb}$ and $\mathrm{Fe}$ in the soil samples of Onitsha South Local Government Area in South East Nigeria. The soil samples collected were examined for the heavy metal contamination using five-step sequential extraction method. The concentrations of the extracted metals were determined using Atomic Absorption Spectrophotometer (AAS). The range of heavy metals extracted fractions for each of five fractions in percentages were as follows; exchangeables $(0.0-3.5 \%)$, bound to carbonates (0.0-4.49\%), bound to Fe-Mn oxides (0.03-4.14\%), bound to organic matter (0.03-3.38\%) and residual (0.0$86.70 \%)$ in wet season; exchangeables (0.0-3.94\%), bound to carbonates $(0.0-4.80 \%)$, bound to Fe-Mn oxides $(0.09-5.19 \%)$, bound to organic matter $(0.09-3.53 \%)$ and residual $(0.0-126.00 \%)$ in dry season. Available heavy metals in the soil studied had mean values $0.52,0.76,1.21,1.24,1.40,9.08$ and 96.37 all in $\mathrm{mgkg}^{-1}$ for $\mathrm{Pb}, \mathrm{Cu}, \mathrm{Zn}, \mathrm{Ni}, \mathrm{Mn}, \mathrm{Cr}$, and Fe respectively for wet season while the mean values in dry season were $0.36,1.21,1.60,1.82,2.45,11.54$ and 143.54 all in $\mathrm{mgkg}^{-1}$ for $\mathrm{Pb}, \mathrm{Cu}, \mathrm{Mn}$, $\mathrm{Ni}, \mathrm{Zn}, \mathrm{Cr}$ and Fe respectively. Mobility factor were $0.22-47.90 \%$ in the two seasons, levels of heavy metals in available forms differ significantly though majority of the extracted toxic metals are found in oxides and the residual fractions and as such may not pose environmental risk due to their relatively low availability and mobility factor. That notwithstanding, soils from studied area should be carefully monitored to prevent the release of these metals due to redox reactions which may make them available to plants through absorption.
\end{abstract}

Keywords: Speciation, Potential Mobility, Soil, Heavy Metals

\section{Introduction}

Soils serve as the most important sink for heavy metal pollutants in terrestrial ecosystems [1] and soil heavy metal pollution is a worldwide problem [2]. Heavy metals commonly originate from two primary sources: natural background (lithogenic) sources and anthropogenic inputs, including metalliferous mining and industries, agrochemicals and mineral fertilizers, vehicle exhaust, sewage sludge and industrial wastes [3]. According to Huang et al. [4], the concentration of heavy metal's solution in the soil, their form of association with other soluble species and the ability of the soil to release them from the solid-phase to the soil solution determine the mobility, bioavailability and the potential toxicity of these metals in the soil. The knowledge of the chemical forms in which those metals are associated reveals the metals behaviour, their mobility and bioavailability within the environment [5 and 6].

Soil contamination with heavy metals is potentially damaging to the ecosystem health [7 and 8]. Unlike some of the organic pollutants, metals cannot be biodegradable and their residence time in the soil can be thousands of years. Therefore, a better understanding and evaluation of the distribution and potential hazards of heavy metals in soils of 
heavily commercialized and industrialized city such as Onitsha South LGA are increasingly needed to ensure the safety of public health. In an effort to improve our way of living through increasing industrialization and human activities, some chemical, physical, biological substances are released into the ecosystem. These substances tend to accumulate to a concentration level that can distort ecological balance, thus becoming harmful to life. However, some of these substances often referred to as pollutants become harmful even at minute concentrations [7].

These metals are known to bio-accumulate in soil and have long persistence time through interaction with soil components and consequently enter into the food chain [9]. However, the particular behavior of trace metals in the environment is determined by their specific chemical forms rather than their total concentration because knowledge of the total content of heavy metals present in the soil provides limited information about their potential behavior and bioavailability [10]. Sequential extraction is the simplest method of identifying the chemical forms in which these heavy metals exist in the soil. In this method, the components that are loosely held in the soil are extracted first, followed by those that are more tightly bonded. When changes occur in the oxidation status of soils and sediments, transformations of metals between their soluble and insoluble chemical forms may occur [11]. This affects the mobility and plant availability of those metals [12].

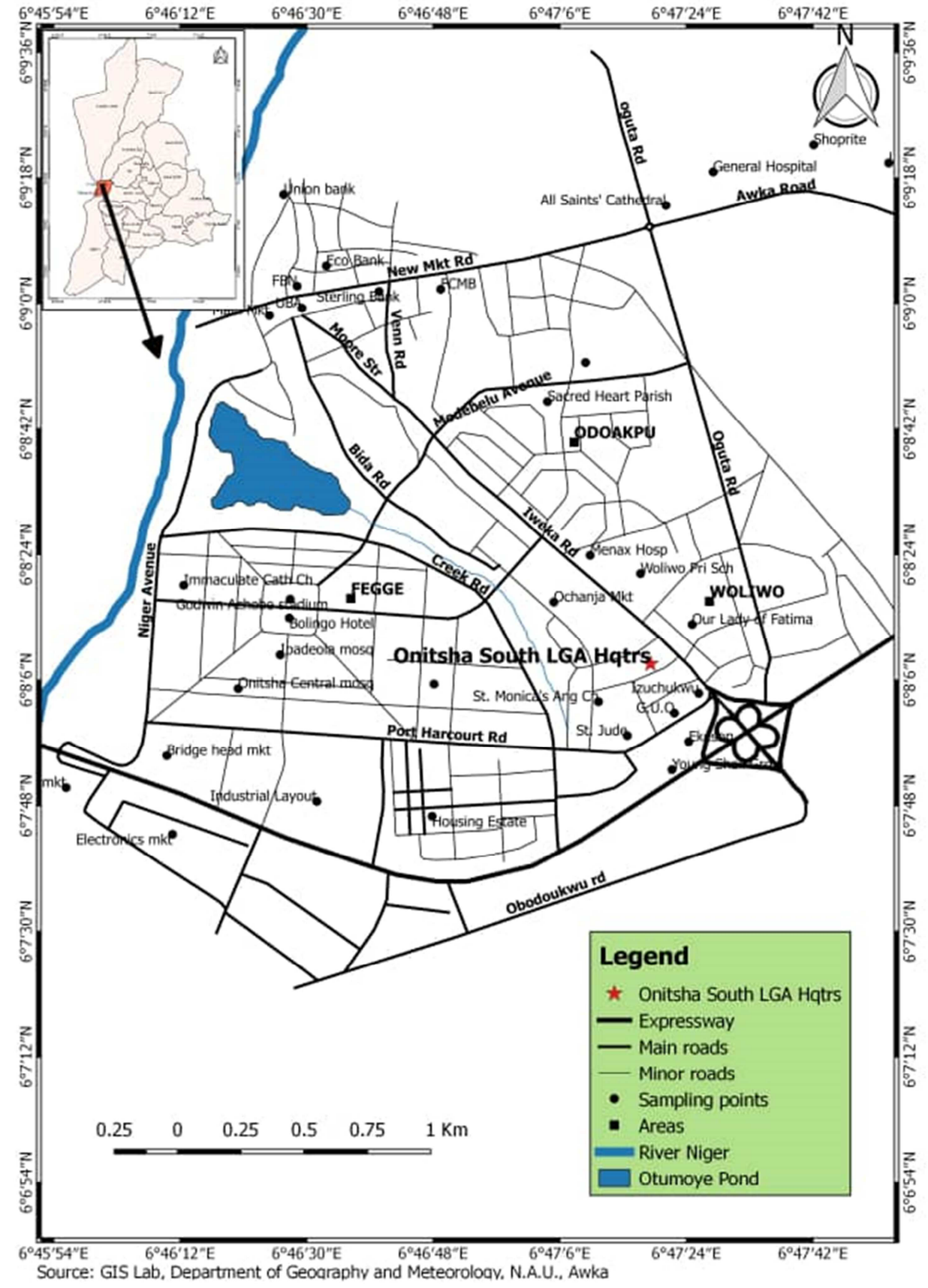

Figure 1. Map of Onitsha South Local Government Area. 
Different types of sequential extraction procedures have been used for this purpose, but the most widely used sequential extraction procedure (SEP) is the Tessier scheme. The theory behind SEP is that the most mobile metals are removed in the first fraction and continue in order of decreasing of mobility. All SEPs facilitate fractionation. Tessier et al. [10] named these fractions exchangeable, carbonate bound, $\mathrm{Fe}$ and $\mathrm{Mn}$ oxide bound, organic matter bound, and residual. These are also often referred to in the literature as exchangeable, weakly absorbed, hydrous-oxide bound, organic bound, and lattice material components, respectively [13]. Typically metals of anthropogenic inputs tend to reside in the first four fractions and metals found in the residual fraction are of natural occurrence in the parent rock [1].

Many research works have been carried out on the speciation of heavy metals in soils in different parts of Nigeria [15 and 16], including Onitsha and its environment, but there is need to periodically re-assess the pollution levels with reference to heavy metal pollutants of such highly industrialized and commercialized area as Onitsha South local government, part of industrial and commercial city of Onitsha of Anambra state. This study will reveal the chemical behavior of heavy metals in the soil environment which is the basis of risk assessment of soils polluted with heavy metals as a result of anthropogenic activities. Speciation and environmental risk assessment studies on heavy metals in soils in this part of the state may have been reported, the results from this study would add to the baseline data for future heavy metal pollution status of soils in the area under study

\section{Materials and Method}

\subsection{Description of the Study Area}

Onitsha South Local Government Area is located between latitudes $06^{\circ} 07^{\prime} 36.12^{\prime} \mathrm{N}$ and $06^{\circ} 38^{\prime} 34^{\prime} \mathrm{N}$ and longitude $06^{\circ} 46^{\prime} 38.50^{\prime} \mathrm{E}$ and $06^{\circ} 59^{\prime} 30^{\prime} \mathrm{E}$ covering an area of $36.12 \mathrm{Km}^{2}$. It is bounded by Onitsha North local government area in the north and in the east Ogbaru L. G. A in the south and in the west by River Niger. Onitsha is the largest urban city in Anambra state with a population of about 561, 066 according to 2006 census. It is also a major commercial town east of the Niger [17].

The climate is classified as humid tropical region. The climate here is classified as Aw by the Köppen-Geiger system. The average annual temperature in Onitsha is $27.0^{\circ} \mathrm{C}$ with rainfall averaging $1828 \mathrm{~mm}$ with monthly relative humidity being at least $86 \%$. The area stands on a low-lying terrain with altitude ranging from $57 \mathrm{~m}$ to $59 \mathrm{~m}$ above sea level. The area is characterized by medium annual temperature, high rainfall, high evapo-transpiration and high relative humidity, which makes it to be classified as humid tropical region [18]. The soil type of Onitsha south L. G. A is hydromorphic [17].

Sampling: Sampling sites were from eleven streets in Odoakpu, Fegge and Woliwo areas in Onitsha south local government area, south-east, Nigeria. Sampling was conducted in two climatic seasons between 2016 and 2018. Fifty five soil samples were collected from top soil using hand trowel and Geographical Position System (GPS) into well labeled polythene bags. Figure 1 showed the sampling points on the study area.

Laboratory analysis: All soil samples in well labeled polythene bags were transported to the laboratory, where they were air-dried for two weeks at ambient temperature, five grab samples from each street was ground using mortar and pistol and sieved to $600 \mu \mathrm{m}$ for heavy metal analysis. Final sample selection from the dried bulk was done using coning and quartering method [19]. Sequential extraction was carried out in triplicate, using $1 \mathrm{~g}$ of air-dried soils. Soil samples were placed in $50 \mathrm{~mL}$ polycarbonate centrifuge tubes mixed in a stepwise manner with various reagents and the suspensions equilibrated as described in Table 1. After each equilibration, the solution and solid phase were separated by centrifugation at $1225 \mathrm{~g}$ for $10 \mathrm{~min}$ and between each successive extractant, the solid residues were suspended in $5 \mathrm{~mL}$ of $0.1 \mathrm{M} \mathrm{NaCI}$, hand shaken and centrifuged to displace extracting solution remaining from the previous step and the supernatant was added to the former extractant.

Table 1. Sequential extraction scheme of Tessier et al.,(1979) for soils and sediments. Step Fraction Extraction.

\author{
1 Exchangeable \\ 2 Acid-soluble ('Carbonate-bound') \\ 3 Reducible ('Fe/Mn-oxide bound') \\ 4 Oxidizable ('Organicallybound + sulphide-bound') \\ 5 Residual ('Residual/Silicate')
}

\author{
$1 \mathrm{~mol} / 1 \mathrm{MgCl}_{2}(\mathrm{pH} 7), 20^{\circ} \mathrm{C}$ \\ $1 \mathrm{~mol} / 1 \mathrm{NaOAc}+\mathrm{HOAc}(\mathrm{pH} \mathrm{5}), 20^{\circ} \mathrm{C}$ \\ $0.04 \mathrm{~mol} / 1 \mathrm{NH}_{2} \mathrm{OH} . \mathrm{HCl}+25 \% \mathrm{HOAc}, 95^{\circ} \mathrm{C}$ \\ $30 \% \mathrm{H}_{2} \mathrm{O}_{2}+0.02 \mathrm{~mol} / 1 \mathrm{HNO}_{3}(\mathrm{pH} 2), 85^{\circ} \mathrm{C} ; 2 \mathrm{~mol} / 1 \mathrm{NH}_{4} \mathrm{OAc}+20 \% \mathrm{HNO}_{3}$ \\ $\mathrm{HF} / \mathrm{HClO}_{4}$
}

\subsection{Quality Assurance of Data}

In order to verify the accuracy of the sequential extraction method, an internal check on the results of the extraction procedure, the recovery of sequential extraction procedure was performed by comparing the sum of the 4 steps (exchangeables + bound to carbonates + Fe-Mn Oxide + residual) from the sequential extraction procedure with the total metal content from the FAAS-assisted acid digestion procedure. The recovery of the sequential extraction procedure was calculated as follows:

$$
\text { Percentage Recovery }=\frac{\text { Fraction } 1+\text { Fraction } 2+\text { Fraction } 3+\text { ResidualFraction } \times 100}{\text { Total digestion }}
$$


All chemicals used were of analytical reagent grade and deionized water was used throughout the experimentation. All plastic materials used were soaked in $10 \%$ Nitric acid. Procedural blanks preparation of standard solutions under clean laboratory environment, calibration of the Buck 211 Flame Atomic Absorption spectrophotometer (FAAS) using certified standards and the analysis of calibrated standards after 10 samples to ensure that the instrument remained calibrated were some of the measures taken during the experimentation

\section{Results and Discussion}

Results of total metal concentration for the following; Mn, $\mathrm{Fe}, \mathrm{Zn}, \mathrm{Pb}$ and $\mathrm{Ni}$ in Woliwo, Odoakpu and Fegge soils in Onitsha South Local Government Area are presented in Tables 2 and 3, while that of sequential extraction of these heavy metals using modified Tessier et al method are presented in percentages in Tables 4 and 5.

Table 2. Total metal concentration $(\mathrm{mg} / \mathrm{kg})$ in the soil for wet season.

\begin{tabular}{|c|c|c|c|c|c|c|c|c|c|}
\hline Location & Mn & $\mathbf{N i}$ & $\mathbf{Z n}$ & Cd & $\mathrm{Cr}$ & $\mathbf{C u}$ & $\mathbf{P b}$ & $\mathbf{F e}$ & Mean \\
\hline 1 & 1.442 & 0.447 & 0.547 & BDL & 7.218 & 0.861 & BDL & 52.520 & 10.506 \\
\hline 2 & 1.821 & 1.600 & 1.638 & BDL & 10.593 & 0.519 & BDL & 111.917 & 21.341 \\
\hline 3 & 1.821 & 1.361 & 1.477 & BDL & 9.126 & 0.531 & BDL & 82.542 & 16.143 \\
\hline 4 & 1.883 & 0.077 & 1.145 & BDL & 8.257 & 0.703 & 0.338 & 81.008 & 13.344 \\
\hline 5 & 1.381 & 0.581 & 1.386 & BDL & 9.937 & 0.207 & 0.250 & 125.150 & 19.842 \\
\hline 6 & 1.283 & 1.513 & 1.437 & BDL & 10.319 & 1.496 & 0.689 & 94.409 & 15.878 \\
\hline 7 & 0.937 & 1.566 & 1.085 & BDL & 11.051 & BDL & BDL & 101.349 & 23.198 \\
\hline 9 & 0.650 & 1.236 & 1.724 & BDL & 6.977 & BDL & BDL & 89.183 & 19.954 \\
\hline 10 & 1.242 & 1.659 & 0.967 & BDL & 6.808 & 0.693 & $\mathrm{BDL}$ & 115.275 & 21.107 \\
\hline 11 & 1.086 & 1.201 & 1.489 & BDL & 7.228 & BDL & BDL & 97.475 & 21.696 \\
\hline Total Metal & 15.302 & 13.621 & 13.657 & 0.000 & 99.923 & 6.369 & 2.076 & 1060.053 & 201.399 \\
\hline Mean & 1.391 & 1.238 & 1.205 & 0.000 & 9.084 & 0.759 & 0.519 & 96.368 & \\
\hline$\pm \mathrm{SD}$ & 0.404 & 0.655 & 0.374 & 0.000 & 1.916 & 0.435 & 0.266 & 20.060 & \\
\hline $\mathrm{CV}$ & 29.016 & 52.865 & 36.338 & 0.000 & 0.000 & 60.069 & 51.308 & 20.816 & \\
\hline
\end{tabular}

$\mathrm{BDL}=$ Below Detectable Limit; $\mathrm{SD}=$ Standard Deviation;

Table 3. Total metal concentration $(\mathrm{mg} / \mathrm{kg})$ in the soil for dry season.

\begin{tabular}{|c|c|c|c|c|c|c|c|c|c|}
\hline \multicolumn{10}{|c|}{ TOTAL METAL CONCENTRATION FOR DRY SEASON (mg/kg) } \\
\hline Sample location & Mn & $\mathbf{N i}$ & $\mathbf{Z n}$ & Cd & $\mathrm{Cr}$ & $\mathrm{Cu}$ & $\mathbf{P b}$ & $\mathbf{F e}$ & Mean \\
\hline 1 & 1.172 & 1.434 & 1.722 & BDL & 10.246 & 1.543 & BDL & 83.316 & 16.572 \\
\hline 2 & 1.947 & 2.103 & 3.088 & $\mathrm{BDL}$ & 11.779 & 0.945 & BDL & 137.900 & 26.294 \\
\hline 3 & 1.872 & 1.792 & 3.234 & BDL & 10.864 & 0.998 & $\mathrm{BDL}$ & 119.608 & 23.061 \\
\hline 4 & 1.286 & 0.277 & 2.696 & BDL & 11.026 & 0.895 & 0.416 & 145.092 & 23.098 \\
\hline 5 & 0.768 & 0.868 & 2.173 & BDL & 12.765 & 0.548 & 0.318 & 136.644 & 22.012 \\
\hline 6 & 1.026 & 1.927 & 2.082 & BDL & 10.936 & 2.041 & 0.880 & 148.708 & 23.943 \\
\hline 7 & 1.841 & 1.873 & 2.578 & $\mathrm{BDL}$ & 17.456 & BDL & BDL & 150.550 & 34.860 \\
\hline 8 & 1.951 & 3.222 & 2.566 & BDL & 13.988 & 1.510 & 0.994 & 149.558 & 24.827 \\
\hline 9 & 1.980 & 1.981 & 2.072 & BDL & 7.973 & BDL & 0.119 & 191.000 & 34.188 \\
\hline 10 & 1.834 & 2.487 & 2.169 & BDL & 9.075 & 1.237 & 0.5643 & 176.167 & 27.647 \\
\hline 11 & 1.911 & 2.182 & 2.591 & $\mathrm{BDL}$ & 10.876 & BDL & 0.206 & 140.433 & 26.367 \\
\hline Total & 17.587 & 20.145 & 26.971 & 0.00 & 126.983 & 9.717 & 3.497 & 1578.977 & 282.868 \\
\hline Mean & 1.599 & 1.822 & 2.452 & 0.00 & 11.544 & 1.212 & 0.357 & 143.543 & \\
\hline$\pm \mathrm{SD}$ & 0.444 & 0.781 & 0.458 & 0.00 & 2.541 & 0.471 & 0.337 & 27.785 & \\
\hline $\mathrm{CV}$ & 27.794 & 43.964 & 18.674 & 0.00 & 0.000 & 38.860 & 48.688 & 19.357 & \\
\hline
\end{tabular}

$\mathrm{SD}=$ standard deviation, $\mathrm{CV}=$ correlation variation, $\mathrm{BDL}=$ below detection limit

\subsection{Total Metal Variation in Rainy and Dry Season}

The total metal concentrations in the soil for rainy and dry seasons are shown in Tables 2 and 3 respectively.

\subsection{Result of Total Heavy Metals in the Soil}

The total level of $\mathrm{Mn}, \mathrm{Ni}, \mathrm{Zn}, \mathrm{Cr}, \mathrm{Cu}, \mathrm{Pb}$ and $\mathrm{Fe}$ was obtained in the mean range of $0.65-1.88,0.08-2.42,0.55-1.64$, $6.81-12.41,0.21-1.50,0.25-0.80,52.52-125.15 \mathrm{mg} / \mathrm{kg}$ for wet season; $0.77-1.98,0.28-3.22,1.72-3.23,7.97-13.99$, $0.54-2.04,0.12-0.99$ and $83.32-191.00 \mathrm{mg} \mathrm{kg}^{-1}$ for dry season respectively (Table 4). The permissible levels of these metals are given in Table 4 according to $\mathrm{W} \mathrm{H} \mathrm{O}$ standard. The levels of all the metals determined were significantly lower $(\mathrm{p}<0.05)$ than the permissible levels.

The studied heavy metals may not pose any environmental risk but may change on long accumulation. However, the mean level of these metals differs significantly $(\mathrm{p}<0.05)$ between the wet and dry seasons: Level in dry season is significantly higher than the level in wet seasons. The result also showed that levels of all the heavy metals determined in dry season were higher than that in rainy season (though not 
significant at $\mathrm{p}=0.05)$. This might be attributed to high precipitation, leaching, erosion and plant uptake which may account for the reduction in heavy metal levels in the rainy season.

Table 4. Average concentrations ( $\mathrm{mg} / \mathrm{kg}$ ) of heavy metals in soil during wet and dry seasons.

\begin{tabular}{lllll}
\hline heavy metals & dry season & wet season & $\begin{array}{l}\text { Average concentration for wet and dry } \\
\text { seasons }\end{array}$ & $\begin{array}{l}\text { WHO/FAO Maximum permissible level of } \\
\text { heavy metals in the soil (mg/kg) }\end{array}$ \\
\hline $\mathrm{Mn}$ & 1.599 & 1.391 & 1.495 & $2000(200-3000)$ \\
$\mathrm{Ni}$ & 1.831 & 1.238 & 1.535 & $50(5-500)$ \\
$\mathrm{Zn}$ & 2.452 & 1.242 & 1.847 & $300(50-300)$ \\
$\mathrm{Cd}$ & $\mathrm{BDL}$ & $\mathrm{BDL}$ & 0.000 & $3(0.03-3)$ \\
$\mathrm{Cr}$ & 11.544 & 9.084 & 10.314 & $100(10-200)$ \\
$\mathrm{Cu}$ & 1.215 & 0.796 & 1.006 & $100(2-250)$ \\
$\mathrm{Pb}$ & 0.500 & 0.519 & 0.510 & $100(2-20)$ \\
$\mathrm{Fe}$ & 143.543 & 96.368 & 119.956 & 50000 \\
\hline
\end{tabular}

\subsection{Results of Speciation Analysis}

Speciation of metals was carried out according to Tessier modified method as described earlier. Tables 5 and 6 show the results of percentage distribution of different heavy metals among various fractions in soil of Onitsha South Local Government Area of Anambra state Nigeria. The exchangeable fraction (F1) contains metal in the ionic form, which have a high mobility and can be drained by water. The fraction related to the carbonates (F2) is bioavailable and can be accumulated in the plants. The fraction related to the oxides of iron and manganese (F3) and that related to organic matter (F4) contain metals enclosed in the matrix. The fraction (F5) contains the inert metals. The percentage of the heavy metals in various fractions (Table 5) in wet season follows this order;

F5: $\mathrm{Fe}>\mathrm{Cr}>\mathrm{Cu}>\mathrm{Mn}>\mathrm{Ni}>\mathrm{Zn}, \mathrm{Pb} ; \mathrm{F} 4: \mathrm{Ni}>\mathrm{Zn}>\mathrm{Cu}>$ $\mathrm{Mn}>\mathrm{Fe}>\mathrm{Cr}>\mathrm{Pb}$; F3: $\mathrm{Mn}>\mathrm{Zn}>\mathrm{Cu}>\mathrm{Cr}>\mathrm{Fe}>\mathrm{Ni}>\mathrm{Pb}$

F2: $\mathrm{Zn}>\mathrm{Cr}>\mathrm{Cu}>\mathrm{Fe}>\mathrm{Ni}>\mathrm{Pb}, \mathrm{Mn}$ and $\mathrm{F} 1: \mathrm{Cr}>\mathrm{Zn}>$ $\mathrm{Ni}>\mathrm{Fe}>\mathrm{Cu}>\mathrm{Pb}, \mathrm{Mn}$

The order for dry season as seen in Table 6 is as follows; $\mathrm{F} 5: \mathrm{Fe}>\mathrm{Cr}>\mathrm{Cu}>\mathrm{Mn}>\mathrm{Ni}>\mathrm{Zn}, \mathrm{Pb} ; \mathrm{F} 4: \mathrm{Zn}>\mathrm{Ni}>\mathrm{Mn}>$ $\mathrm{Cu}>\mathrm{Fe}>\mathrm{Cr}>\mathrm{Pb} \mathrm{F} 3: \mathrm{Ni}>\mathrm{Mn}>\mathrm{Zn}>\mathrm{Cr}>\mathrm{Cu}>\mathrm{Ni}>\mathrm{Pb}$

F2: $\mathrm{Zn}>\mathrm{Cu}>\mathrm{Cr}>\mathrm{Fe}>\mathrm{Ni}>\mathrm{Mn}, \mathrm{Pb}$ and $\mathrm{F} 1: \mathrm{Zn}>\mathrm{Cr}>$ $\mathrm{Cu}>\mathrm{Fe}>\mathrm{Ni}>\mathrm{Mn}, \mathrm{Pb}$

In both seasons, $\mathrm{Fe}$ has greater percentage of the fractions in F5. Others did not follow a particular pattern.

Table 5. Analysis of heavy metals speciation in wet season (\%).

\begin{tabular}{|c|c|c|c|c|c|c|c|c|}
\hline Fraction & Description & Mn & $\mathrm{Ni}$ & $\mathbf{Z n}$ & $\mathrm{Cr}$ & $\mathrm{Cu}$ & $\overline{P b}$ & $\mathbf{F e}$ \\
\hline 1 & Exchangeable & 0.00 & 0.17 & 0.29 & 1.70 & 0.09 & 0.04 & 3.50 \\
\hline 2 & Bound to carbonates & 0.00 & 0.18 & 0.38 & 1.17 & 0.09 & 0.05 & 4.49 \\
\hline 3 & Bound to oxides & 0.49 & 0.46 & 0.43 & 1.75 & 0.17 & 0.03 & 4.14 \\
\hline 4 & Bound to organics & 0.38 & 0.70 & 0.31 & 0.39 & 0.17 & 0.03 & 3.38 \\
\hline \multirow[t]{3}{*}{5} & Residual or inert & 0.82 & 0.48 & 0.00 & 4.32 & 0.24 & 0.06 & 86.70 \\
\hline & Sum of concentration of metals $(\mathrm{mg} / \mathrm{kg})$ & 15.30 & 13.62 & 13.66 & 99.92 & 6.37 & 2.08 & 1060.05 \\
\hline & Potential mobility & 0.27 & 47.90 & 47.28 & 31.20 & 31.23 & 41.08 & 8.01 \\
\hline
\end{tabular}

Table 6. Analysis of heavy metals speciation in Dry season (\%).

\begin{tabular}{|c|c|c|c|c|c|c|c|c|}
\hline Fraction & Description & Mn & $\mathrm{Ni}$ & $\mathbf{Z n}$ & $\mathrm{Cr}$ & $\mathbf{C u}$ & $\mathbf{P b}$ & $\mathbf{F e}$ \\
\hline 1 & Exchangeable & 0.00 & 0.20 & 0.37 & 1.89 & 0.12 & 0.08 & 3.94 \\
\hline 2 & Bound to carbonates & 0.00 & 0.21 & 0.62 & 1.28 & 0.12 & 0.07 & 4.80 \\
\hline 3 & Bound to oxides & 0.63 & 0.80 & 0.93 & 2.23 & 0.24 & 0.09 & 5.19 \\
\hline 4 & Bound to organics & 0.50 & 0.84 & 0.60 & 0.56 & 0.27 & 0.09 & 3.53 \\
\hline \multirow[t]{3}{*}{5} & Residual or inert & 1.02 & 0.75 & 0.00 & 5.69 & 0.41 & 0.07 & 126.00 \\
\hline & Sum of concentration of metals $(\mathrm{mg} / \mathrm{kg})$ & 17.59 & 20.15 & 26.97 & 126.98 & 9.72 & 3.50 & 1578.98 \\
\hline & Potential mobility & 0.22 & 14.43 & 40.14 & 27.91 & 28.17 & 38.74 & 6.44 \\
\hline
\end{tabular}

Metal chemical speciation carried out by sequential extraction of the metals is essential to the metal mobility [10]. The order of mobility of the metals considering their abundance in the fractions is: exchangeable $>$ bound to carbonate $>$ bound to oxides $>$ bound to organics $>$ residual [10]. Oxides exist as nodules and cement between particles. These oxides hold trace metals and can be mobilized under reducing and acidic conditions. The organic phase is relatively stable in nature but can be mobilized under strong oxidizing conditions due to degradation of organic matter [20]. Fe has high abundance in exchangeable and residual fractions in all the samples. The abundance of $\mathrm{Cr}$ in exchangeable phase is $1.70 \%$ and $1.89 \%$ respectively in wet and dry seasons while in the residual fraction the abundance was $4.32 \%$ and $5.69 \%$ in both seasons. Abundance of $\mathrm{Cr}$ was least in bound to organics in both seasons. This means that $\mathrm{Cr}$ was moderately mobile in this environment. $\mathrm{Zn}$ is mostly abundant bound to oxides with abundance of $0.43 \%$ and $0.97 \%$ in wet and dry seasons respectively; these were similar to what was obtained in other fractions with the exception of bound to residual fraction where the abundances were $0.00 \%$ in both seasons. $\mathrm{Zn}$ in this environment was 
more mobile than other metals that were mostly abundant in the residual fraction. Copper can easily complex with organic matters because of high formation of organic- $\mathrm{Cu}$ compounds [20]. The result of sequential extraction obtained shows that the concentration of $\mathrm{Cu}$ in the environment is not much but amongst the available concentrations. $\mathrm{Cu}$ was one of the most abundant in both seasons is in the residual fraction $(0.24 \%$ and $0.41 \%$ in wet and dry seasons respectively). The abundance of $\mathrm{Cu}$ in other fractions was a little much more below what was obtained in residual fraction.

Heavy metals with high abundance in the phase bound to organics are more available than heavy metals in the residual fraction [21]. Apart from $\mathrm{Fe}$ which generally has higher percentage in all fractions, the concentration of $\mathrm{Ni}$ in both seasons in the bound to Organics phase is much higher than other metals studied $(0.70 \%$ in wet season and $0.84 \%$ in dry season). $\mathrm{Mn}, \mathrm{Cr}, \mathrm{Cu}$ and $\mathrm{Fe}$, as shown in Tables 5 and 6 had the highest abundance in the residual fraction with Fe being the highest in both seasons ( $\mathrm{Fe} 86.70 \%$ in wet season and $126.00 \%$ in dry season). This agrees with Omuku et al., 2012, who reported that $\mathrm{Fe}, \mathrm{Mn}$ and $\mathrm{Ni}$ were mostly associated with the residual phase. The results of the sequential extraction show that more than $80 \%$ of all the fractions of $\mathrm{Fe}$ are strongly retained in the residual phase in all soils followed by $\mathrm{Mn}$ and $\mathrm{Cr}$. These heavy metals are contained in the crystal lattices of minerals with strong bindings and consequently they will not be released into the environment. $\mathrm{Mn}$ is not associated with exchangeables and bound to carbonates and as such will not be easily available in the soils studied, the available proportions are associated to oxides, organics and residual fractions. Mn would be released from oxides and if conditions became acidic, it would be released from carbonates. Therefore, such changes could only be expected from an anthropogenic impact. The abundance of $\mathrm{Pb}$ is very low and are available in all fractions though fewer in residual fraction.

Metals present in the residual fraction are a measure of the degree of environmental pollution. The higher the metals present in this fraction, the lower the degree of pollution [22]. Sum of concentrations of metals in different geochemical phases can be used to express the potential mobility of metals [20]. The potential mobility of a metal can be assessed by adding up the results of the exchangeable phase, carbonate phase, oxide, and organic phase of that metal [23]. The exchangeable phase represents the mobile and bioavailable heavy metal fraction and that is why in Figures 1 and 2 the potential mobility of the metals are higher with metals whose the exchangeable fraction is higher than other fractions. In the exchangeable phase, the heavy metals have the more labile bounds and can be easily released into the environment. The presence of heavy metals in this phase where they can be taken up by plants from the soils is the most hazardous to the ecosystem [20]. In our soils, $\mathrm{Fe}$ is much abundant [24] and is present in this phase. From the result of the sequential extraction in all the soil samples studied, Zn was mostly abundant in the exchangeable fraction and the abundance was $0.00 \%$ in the residual fraction. Low abundance of a metal in the residual phase compared with its abundance in other geochemical phases indicates higher mobility of the metal in the environment. This explains that $\mathrm{Zn}$ would easily be released to the environment and will exhibit high toxic. High abundance of $\mathrm{Zn}$ bound to oxides accounts for the high potential mobility of $\mathrm{Zn} 47.28 \%$ and $40.14 \%$ (Figures 2 and 3 ). The potential mobility of heavy metals with high abundance in residual fraction were: $\mathrm{Mn} 0.27 \%$ and $0.22 \%$; Fe $8.01 \%$ and $6.44 \%$ (in wet and dry seasons respectively). These values were low compared with the values obtained for heavy metals that were more abundant in other geochemical phases.

\subsection{Potential Mobility of Heavy Metals in Soil}

Average potential mobility of the heavy metals in the soils for two seasons are shown in (Tables 5 and 6). Graphical representations for the seasons are equally shown in Figures 2 and 3.

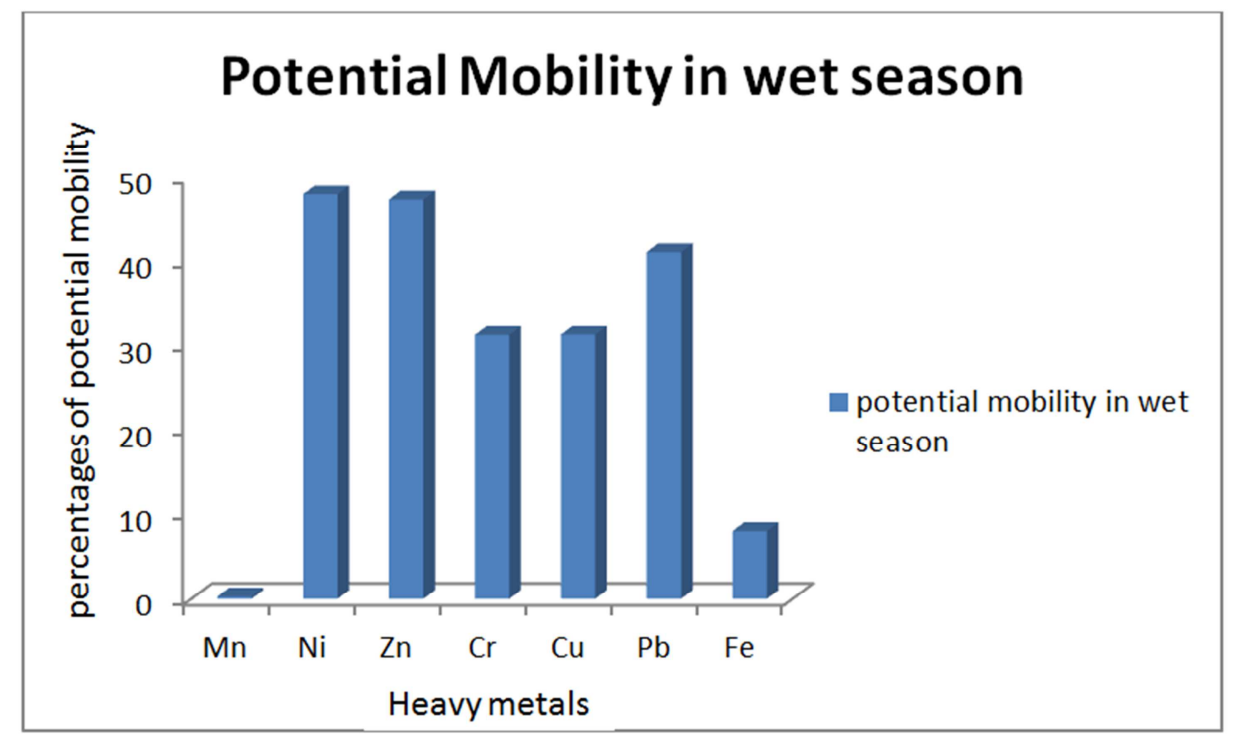

Figure 2. Potential mobility of heavy metals in wet season. 




Figure 3. Potential mobility of heavy metals in dry season.

The potential mobility of $\mathrm{Zn}$ was $47.28 \%$ and $40.14 \%$ in wet and dry season respectively (Figures 2 and 3). High potential mobility indicates high reduction in concentration in the soil. $\mathrm{Zn}$ is mostly abundant in bound to oxides in both seasons. Under reducing and acidic conditions, Zn will easily be released to the environment. Ni has the highest mobility in wet season $(47.90 \%)$, this means that in this season $\mathrm{Ni}$ will be very much available in the soil than in the dry season where it shows a mobility of $14.43 \%$. Compared with other metals that were mostly abundant in the residue fraction $\mathrm{Ni}$ was more available and toxic in the environment in wet season. $\mathrm{Pb}$ equally that showed a high mobility in the soil in both seasons.

The average potential mobility of $\mathrm{Cu}$ is $31.23 \%$ in wet season and $28.17 \%$ in dry season. Under strong oxidizing conditions, due to degradation of organic matter, $\mathrm{Cu}$ might be available in the environment. $\mathrm{Cr}$ showed similar result as $\mathrm{Cu}$ in both seasons. More metals were present in bound to oxide fraction than in the other fractions which show that the degree of pollution in the environment is presently low. $\mathrm{Mn}$ and $\mathrm{Fe}$ had the least average potential mobility $\mathrm{Mn}$ $(0.27 \%$ and $0.22 \%), \mathrm{Fe}(8.01 \%$ and $6.44 \%)$ in wet and dry season respectively. Change in concentration was low because $\mathrm{Mn}$ and $\mathrm{Fe}$ in soil in this environment were relatively immobile and predominantly in the residual fraction.

From Tables 5 and 6, and Figures 2 and 3, the order of average potential mobility for soil agrees with the percentage reduction in concentration. Also as was revealed from the results, the potential mobility in wet season was higher than the dry season. This would be attributed to the fewer intakes of dissolved ions from flood rain water. Highaverage potential mobility indicates high percentage reduction in concentration. Metals with anthropogenic origin are mainly extracted in the first step of sequential extraction procedures while lithogenic metals are found in the last step of the process corresponding to the residual fraction [25]. Metals such as $\mathrm{Zn}, \mathrm{Ni}$ and $\mathrm{Pb}$ as shown in the results above were mostly of anthropogenic origin due to commercial, industrial and domestic activities. Heavy metals such Fe and Mn were highly abundant in the residual fraction, implying that they were not derived from anthropogenic sources.

\section{Conclusion}

The soils of the study area are ferruginous soils, meaning they have high Fe content. This explains why the soils showed high $\mathrm{Fe}$ in the residual fraction. The $\mathrm{pH}$ of the soils was slightly acidic. This study served to evaluate the distribution, retention, and release of $\mathrm{Mn}, \mathrm{Ni}, \mathrm{Zn}, \mathrm{Cr}, \mathrm{Cu}$, $\mathrm{Pb}$ and $\mathrm{Fe}$ in the selected soils of the Onitsha South Local Government Area. The results obtained from speciation studies showed that some of the metals considered had the highest abundance in the residual fraction. This indicates that the metals were immobile. The largest proportions for $\mathrm{Cr}, \mathrm{Mn}$ and $\mathrm{Fe}$ were extracted in the residual phase, in which metals are strongly retained in the soil minerals. This shows that soils in the environment were not likely to be polluted by these metals. $\mathrm{Zn}, \mathrm{Ni}$ and $\mathrm{Pb}$ were found to be highly abundant in the exchangeable, bound to carbonates and oxide fractions, indicating that they could be easily released to the environment from soil. They were also likely to cause toxicity in the environment. The average potential mobility of $\mathrm{Zn}, \mathrm{Ni}$ and $\mathrm{Pb}$ in the soils samples studied were relatively high implying that under favourable conditions they can be released to pollute the environment. The average potential mobility of the metals arranged in decreasing order was as: $\mathrm{Ni}>\mathrm{Zn}>\mathrm{Pb}>\mathrm{Cu}>\mathrm{Cr}>\mathrm{Fe}>\mathrm{Mn}$ and $\mathrm{Zn}>\mathrm{Pb}>\mathrm{Cu}>\mathrm{Cr}>\mathrm{Ni}>\mathrm{Fe}>\mathrm{Mn}$ in wet and dry seasons respectively. The results of the speciation have given the present status of metal pollution and the potential pollutants in the studied area. 


\section{References}

[1] Li X. Y., Liu L. J., Wang Y. G., Luo G. P., Chen X., Yang X. L. (2013). Heavy metal contamination of urban soil in an old industrial city (Shenyang) in Northeast China. Geoderma. 192: $50-58$

[2] Liu X. M., Wu J. J., Xu J. M. (2006). Characterizing the risk assessment of heavy metals and sampling uncertainty analysis in paddy field by geostatistics and GIS. Environ Pollution, 141: $257-264$

[3] Zhang C. S. (2006), Using multivariate analyses and GIS to identify pollutants and their spatial patterns in urban soils in Galway, Ireland. Environmental Pollution. 142: 501-511.

[4] Huang, S. H, Li, Q, Yang, Y, Yuan, C. Y, Ouyang, K, Wang, B and Wan, S (2017). Accumulation Characteristics and Chemical Speciation of $\mathrm{Cd}, \mathrm{Zn}$ and $\mathrm{Pb}$ in Soils Impacted by a $\mathrm{Pb}-\mathrm{Zn}$ Mining Area. 66 (1-2): 53-58.

[5] Rieuwerts, J. S. (2007). The mobility and bioavailability of trace metals in tropical soils: a review, Chemical Speciation and Bioavailability, 19 (2); 75-85,

[6] Romic, M. (2012) Bioavailability of Trace Metals in Terrestrial Environment: Methodological Issues. European Chemical Bulletin, 1, 489-493.

[7] Remon, E., Bouchardon, J and Cornier, B. (2005). Soil characteristics, heavy metal availability and vegetation recovery at a former metallurgical landfill: implications in risk assessment and site restoration. Environmental Pollution, 137: 316-323

[8] Chai, X., Takayuki, S and Cao, X. (2007). Characteristics and mobility of heavy metals in an MSW landfill: implications in risk assessment and reclamation. Journal of Hazardous Materials, 144: 485-491

[9] Vasiliadou, S and Dordas, C. (2009). Increased concentration of soil cadmium effects on plant growth, dry matter accumulation, $\mathrm{Cd}$, and $\mathrm{Zn}$ uptake of different Tobacco cultivars (Nicotiana tabacum L). International Journal of Phytoremadiation 11: 115-130.

[10] Tessier, A, Campbell, P. G. C and Blsson, M. (1979). Sequential extraction procedure for the speciation of particulate trace metals. Analytical Chemistry. 52 (1): 45-53

[11] Adewuyi, G. O and Osobamiro, M. T. (2016). Chemical Speciation and Potential Mobility of Some Toxic Metals in Tropical Agricultural Soil. Research Journal of Environmental Toxicology, 10: 159-165.

[12] Ogunfowokan, A. O., Obisanya, J. F. \& Ogunkoya, O. O. (2013). Salinity and sodium hazards of three streams of different agricultural land use systems in Ile-Ife, Nigeria. Applied Water Science 3: 19-28.

[13] Maiz, I., Arambarri, I., Garcia, R and Millán, E. (2000).
"Evaluation of Heavy Metal Availability in Polluted Soils by Two Sequential Extraction Procedures Using Factor Analysis," Environmental Pollution, 110 (1): 3-9

[14] Ratuzny, T., Gong, Z and Wilke, B. M.(2009). Total concentrations and speciation of heavy metals in soils of the ShenyangZhangshi irrigation area, China. Environmental Monitoring and Assessment. 156 (1-4): 171-180.

[15] Eddy, N. O., Odoemelem, S. A and Mbaba, A. (2006). Elemental composition of soil in some dumpsites. Electronic Journal of Environmental Agricultural Food Chemistry, 5: 1002-1019.

[16] Onweremadu, E. U, Osuji, G. E, Eshett, E. T. (2007). Characterization of owner managed farms of Abia and Imo states for sustainable crop production in South Eastern Nigeria. Journal of American Science, 3: 28-37.

[17] Ejikeme, J. O, Igbokwe, J. I, Igbokwe, E. C and Ezeomedo, I. C. (2014). The Revision of 1: 50000 Topographic Map of Onitsha Metropolis, Anambra State, Nigeria Using Nigeriasat1 imagery. International journal of Engineering and Management science 5 (4): 235-240

[18] Akanni, C. O. (1992). Climate. In: Onakomaya, S. O, Oyesiku, K, jegede, j, editors. Ogun state in maps. Ibadan: Rex Charles Publisher: p187.

[19] Fifield, F. W. and Kealey, D. (1990). Principles and Practice of Analytical Chemistry. Published by Springer 10: 13

[20] Ashraf, M, Maah, Mohd and Yusoff, Ismail (2012). Chemical Speciation and Potential Mobility of Heavy Metals in the Soil of Former Tin Mining Catchment. The Scientific World Journal, 2012: 125608

[21] Liang, S., Wang, X., Li, Z., Gao, N and Sun, H.(2014) Fractionation of heavy metals in contaminated soils surrounding non-ferrous metals smelting area in the North China Plain, Chemical Speciation and Bioavailability, 26 (1); 59-64.

[22] Howari FM, Banat KM. Assessment of Fe, $\mathrm{Zn}, \mathrm{Cd}, \mathrm{Hg}$, and $\mathrm{Pb}$ in the Jordan and Yarmouk River sediments in relation to their physicochemical propperties and sequential extraction characterization. Water, Air, and Soil Pollution. 2001; 132 (12): $43-59$.

[23] Haung, J., Haung, R., Jiao J. J and Chen, K. (2007). Speciation and mobility of heavy metals in mud, in coastal reclamation areas in Chenzhen, China. Environment Geology. 53 (1): 221-228.

[24] Igwe, Charles, Zarei, Mojtaba and Stahr, Karl. (2009). Colloidal stability in some tropical soils of southeastern Nigeria as affected by iron and aluminium oxides. Catena. 77: $232-237$

[25] Ramirez, M., Massolo, S., Frache, R and Correa, J. A. (2005) Metal speciation and environmental impact on sandy beaches due to El Salvador copper mine, Chile. Marine Pollution Bulletin. 50 (1): 62-72. 